\title{
Intracerebral haemorrhage
}

\author{
Adnan I Qureshi, MD, \\ Zeenat Qureshi Stroke Research Center, Department of Neurology and Neurosurgery, University \\ of Minnesota, MN, Minnesota, USA
}

A David Mendelow, FRCS, and Department of Neurosurgery, University of Newcastle, Newcastle, UK

Daniel F Hanley, MD

Division of Brain Injury Outcomes, Johns Hopkins Medical Institutions, Baltimore, MD, USA

\section{Abstract}

Intracerebral haemorrhage is an important public health problem leading to high rates of death and disability in adults. Although the number of hospital admissions for intracerebral haemorrhage has increased worldwide in the past 10 years, mortality has not fallen. Results of clinical trials and observational studies suggest that coordinated primary and specialty care is associated with lower mortality than is typical community practice. Development of treatment goals for critical care, and new sequences of care and specialty practice can improve outcome after intracerebral haemorrhage. Specific treatment approaches include early diagnosis and haemostasis, aggressive management of blood pressure, open surgical and minimally invasive surgical techniques to remove clot, techniques to remove intraventricular blood, and management of intracranial pressure. These approaches improve clinical management of patients with intracerebral haemorrhage and promise to reduce mortality and increase functional survival.

\section{Introduction}

Non-traumatic intracerebral haemorrhage results from rupture of blood vessels in the brain. It is a major public health problem ${ }^{1}$ with an annual incidence of $10-30$ per 100000 population, ${ }^{1,2}$ accounting for 2 million $(10-15 \%)^{3}$ of about 15 million strokes worldwide each year. ${ }^{4}$ Hospital admissions for intracerebral haemorrhage have in creased by $18 \%$ in the past 10 years, ${ }^{5}$ probably because of increases in the number of elderly people, ${ }^{6}$ many of whom lack adequate blood-pressure control, and the increasing use of anticoagulants, thrombolytics, and antiplatelet agents. Mexican Americans, Latin Americans, African Americans, Native Americans, Japanese people, and Chinese people have higher incidences than do white Americans. ${ }^{2,7-9}$ These differences are mostly seen in the incidence of deep intracerebral haemorrhage and are most prominent in young and middle-aged people. Incidence might have decreased in some populations with improved access to medical care and blood-pressure control. ${ }^{8-10}$

Primary and secondary (anticoagulant-induced) intra-cerebral haemorrhage have similar underlying pathological changes. ${ }^{11}$ Intracerebral haemorrhage commonly affects cerebral lobes, the basal ganglia, the thalamus, the brain stem (predominantly the pons), and the

Correspondence to: Dr Adnan I Qureshi, Department of Neurology, University of Minnesota, 12-100 PWB, 516 Delaware St SE, Minneapolis, MN 55455, USA, qureshi@umn.edu.

Contributors

All authors contributed equally to the preparation of this Seminar. 
cerebellum as a result of ruptured vessels affected by hypertension-related degenerative changes or cerebral amyloid angiopathy. ${ }^{1}$ Most bleeding in hyper tension-related intracerebral haemorrhage is at or near the bifurcation of small penetrating arteries that originate from basilar arteries or the anterior, middle, or posterior cerebral arteries. ${ }^{12}$ Small artery branches of 50-700 $\mu \mathrm{m}$ in diameter often have multiple sites of rupture; some are associated with layers of platelet and fibrin aggregates. These lesions are characterised by breakage of elastic lamina, atrophy and fragmentation of smooth muscle, dissections, and granular or vesicular cellular degeneration. ${ }^{12,13}$ Severe atherosclerosis including lipid deposition can affect elderly patients in particular. Fibrinoid necrosis of the subendothelium with subsequent focal dilatations (micro aneurysms) leads to rupture in a small proportion of patients. ${ }^{12}$

Cerebral amyloid angiopathy is characterised by the deposition of amyloid- $\beta$ peptide and degenerative changes (microaneurysm formation, concentric splitting, chronic inflammatory infiltrates, and fibrinoid necrosis) in the capillaries, arterioles, and small and medium sized arteries of the cerebral cortex, leptomeninges, and cerebellum. ${ }^{14}$ Cerebral amyloid angiopathy leads to sporadic intracerebral haemorrhage in elderly people, commonly associated with variations in the gene encoding apolipoprotein E, and a familial syndrome in young patients, typically associated with mutations in the gene encoding amyloid precursor protein. ${ }^{15}$ White-matter abnormalities (eg, leukoariosis) seem to increase the risk of both sporadic and familial intracerebral haemorrhage, suggesting a shared vascular pathogenesis. ${ }^{16,17}$

Intracerebral haemorrhage associated with the taking of oral anticoagulants typically affects patients with vasculopathies related to either chronic hypertension or cerebral amyloid angiopathy, which might represent exacerbation of an existing risk of clinical and subclinical disease. ${ }^{16}$

\section{Pathophysiology}

The regions surrounding haematomas are characterised by oedema, apoptosis and necrosis, and inflammatory cells. ${ }^{18}$ Haematomas induce injury (figure 1) by mechanical disruption of the neurons and glia, ${ }^{1}$ followed by mechanical deformation causing oligaemia, neurotransmitter release, mitochondrial dysfunction, and membrane depolarisation. ${ }^{19-21}$ Dependent on the severity of mitochondrial dysfunction, the results of injury range from temporary metabolic suppression (hibernation phase) to cellular swelling and necrosis. A secondary cascade of injury is started by products of coagulation and haemoglobin breakdown, in particular thrombin, which activate of microglia by $4 \mathrm{~h}$ after injury. ${ }^{22-25}$ Activated microglia ${ }^{26}$ release products that induce breakdown of the blood-brain barrier, vasogenic oedema, and apoptosis in neurons and glia. ${ }^{27-32}$

Haemostasis is initiated by local activation of haemostatic pathways and mechanical tamponade. ${ }^{33,34}$ However, about $73 \%$ of patients assessed within $3 \mathrm{~h}$ of symptom onset have some degree of haematoma enlargement ${ }^{35}$ and up to $35 \%$ have clinically prominent enlargement ${ }^{35}$ (figure 2). Most haematoma enlargement occurs within $3 \mathrm{~h}$, although enlargement can occur up to $12 \mathrm{~h}$ after onset. ${ }^{36,37}$ Perihaematomal oedema increases in volume by about $75 \%$ in the first $24 \mathrm{~h}$ after intracerebral haemorrhage, ${ }^{38}$ peaks around $5-6$ days, ${ }^{39}$ and lasts up to 14 days. ${ }^{40}$ Early large oedema volume relative to haematoma volume makes the greatest contribution to outcome. ${ }^{41}$ However, oedema that is small initially can increase in volume in the first $24 \mathrm{~h}$ after haemorrhage. ${ }^{38}$ An acute hypometabolic and hypoperfusion (hibernation) phase, ${ }^{42,43}$ with mitochondrial dysfunction ${ }^{44}$ and metabolic failure, ${ }^{45}$ has been reported in the region surrounding the haematoma (figure 3 ). Regional hypoperfusion in clinical ${ }^{46,47}$ and experimental studies ${ }^{48,49}$ does not always seem severe 
enough to induce ischaemia and might be secondary to hypometabolism. In the presence of very high intracranial pressure and low cerebral perfusion pressure, the risk of global ischaemia is high. A variable reperfusion phase lasts from 2 days to 14 days, and a normalisation phase develops after 14 days, with re-establishment of normal cerebral blood flow in all viable regions.

\section{Diagnosis, clinical features, and outcomes}

Although CT scanning is the first-line diagnostic approach, MRI with gradient echo can detect hyperacute intracerebral haemorrhage with equal sensitivity and overall accuracy ${ }^{50,51}$ and is more accurate for the detection of microhaemorrhages (figure 4). Perihaematomal extravasation of intravenous contrast on CT scan can detect ongoing bleeding. ${ }^{52,53}$ Cerebral angiography is needed to diagnose secondary causes of intracerebral haemorrhage, such as aneurysms, arteriovenous malformations, dural venous thromboses, and vasculitis $1,34,54,55$ (figure 5). MRI and magnetic-resonance angiography can also identify secondary causes of intracerebral haemorrhage such as cavernous malformations, ${ }^{55}$ although their sensitivity is not well established.

Classic presentations, such as rapid-onset focal neurological deficits, decreased consciousness, and signs of brainstem dysfunction, are related to the size and location of haematoma. ${ }^{1}$ Neurological deterioration is common before ${ }^{56}$ and during ${ }^{57}$ hospital admission and is related to early haematoma enlargement or late worsening of oedema. ${ }^{58}$ Several descriptors of disease severity are predictive of early death, including age, initial score on the Glasgow coma scale (GCS), haematoma volume, ventricular blood volume, ${ }^{59}$ and haematoma enlargement. ${ }^{35}$

Mortality at 3 months was $34 \%$ in a review of 586 patients with intracerebral haemorrhage from 30 centres. $^{60}$ In other studies it was $31 \%$ at 7 days, $59 \%$ at 1 year, $82 \%$ at 10 years, and more than $90 \%$ at 16 years. ${ }^{61,62}$ Subsequent risk of other cardiovascular events was $4 \%$ for all stroke, $2 \%$ for intracerebral haemorrhage, and $1 \%$ for ischaemic stroke per patient-year. ${ }^{63}$ Patients with a lobar haemorrhage had a high rate of recurrence (4\% per patient-year). Asymptomatic disease progression is particularly common when microbleeds and white matter abnormalities are taken into account. ${ }^{64}$ Effects of recurrent bleeding can be changed by antihypertensive treatment; ${ }^{65}$ whether progressive functional impairments are equally treatable is unknown. 66

\section{Management}

\section{Overall principles}

In a review of 1421 patients with intracerebral haemorrhage, care limitations or withdrawal of life-sustaining interventions was the most common (in 68\%) cause of death. ${ }^{67}$ A statewide survey in the $\mathrm{USA}^{68}$ showed that the odds of dying in hospital were associated with the frequency of use of do-not-resuscitate orders. In another study, in-hospital mortality was lower in patients treated in an intensive-care neurology unit. ${ }^{69}$ These studies provide indirect evidence that aggressive medical management and specialist care can improve the overall outcome in patients with intracerebral haemorrhage. In the USA, admissions for haemorrhage to urban teaching hospitals increased from 30\% in 1990-91 to 49\% in 2000$01 .^{5}$ Mortality was decreased substantially for patients admitted to urban teaching hospitals but not urban non-teaching hospitals and rural hospitals, suggesting that changing trends in admissions might be beneficial. ${ }^{5}$ Trials addressing a single severity factor (haemorrhage volume $^{70}$ or haematoma enlargement ${ }^{71}$ ) have been physiologically successful but without clinical benefit. These results emphasise that a single treatment approach might accomplish its physiological goal but be insufficient to produce clinical benefit, thus opening the 
possibility that well organised, multimodal therapy addressing each of the modifiable factors -haematoma volume, ventricular blood, and haematoma enlargement - might be needed. ${ }^{72}$

\section{Early assessment and management}

Airway support, ${ }^{1}$ blood-pressure control, ${ }^{73}$ intracranial pressure treatment, ${ }^{74}$ and anticoagulation reversal ${ }^{75}$ are commonly started in emergency departments, which are also the site of many first neurosurgical consultations for patients with intracerebral haemorrhage. ${ }^{1}$ Observational studies show that about $30 \%$ of patients with supra tentorial haemorrhage and almost all patients with brainstem or cerebellar haemorrhage have either decreased consciousness or bulbar muscle dysfunction necessitating intubation. ${ }^{76}$ Rapid deterioration, clinical evidence of transtentorial herniation, or mass-effect or obstructive hydro cephalus on neuroimaging should mandate an emergent neurosurgical consultation for possible intra ventricular catheter placement or surgical evacuation and concomitant use of hyperventilation and intravenous mannitol ${ }^{77-79}$ (figure 5). The risk of neurological deterioration and cardiovascular instability is greatest in the first $24 \mathrm{~h}$ after symptom onset, ${ }^{80}$ and frequent assessment of patients' neurological status and haemodynamic variables in dedicated intensive-care units is needed.

\section{Acute haemostatic treatment}

Activated recombinant factor VII (fVIIa) promotes haemostasis at sites of vascular injury and limits haematoma enlargement after intracerebral haemorrhage. A randomised, doubleblind, placebo-controlled phase II trial ${ }^{81}$ treated 399 patients within $3 \mathrm{~h}$ of onset with placebo or $40 \mu \mathrm{m} / \mathrm{kg}, 80 \mu \mathrm{m} / \mathrm{kg}$, or $160 \mu \mathrm{g} / \mathrm{kg}$ of fVIIa. Overall, the mean increase in haematoma volume was $29 \%$ in the placebo group, compared with 11-16\% in the groups given fVIIa. Mortality at 90 days was $29 \%$ for patients who received placebo and $18 \%$ for those who received fVIIa. The phase III fVIIa for Acute Hemorrhagic Stroke Treatment (FAST) trial ${ }^{71}$ assessed the efficacy of fVIIa in patients with intracerebral haemorrhage who presented within $3 \mathrm{~h}$ of symptom onset. Of 821 patients, 263 received placebo, 265 received $20 \mu \mathrm{g} / \mathrm{kg}$, and 293 received $80 \mu \mathrm{g} / \mathrm{kg}$ of fVIIa. The ability of fVIIa to limit expansion was similar to the initial trial for both the $20 \mu \mathrm{g} / \mathrm{kg}$ and $80 \mu \mathrm{g} / \mathrm{kg}$ doses. However, at 3 months, $24 \%$ given placebo had died or had disability compared with $26 \%$ and $29 \%$ of patients given $20 \mu \mathrm{g} / \mathrm{kg}$ and $80 \mu \mathrm{g} / \mathrm{kg}$ of fVIIa, respectively; mortality was not different between the groups. The rate of arterial thrombosis was higher in patients treated with $80 \mu \mathrm{g} / \mathrm{kg}$ of fVIIa (10\%) than in those treated with placebo (5\%) or $20 \mu \mathrm{g} / \mathrm{kg}$ of fVIIa (6\%). Thus, this pivotal trial of fVIIa did not confirm better functional outcomes despite producing a significant reduction in rate of haematoma expansion. The absence of major benefit for fVIIa, despite its ability to stabilise bleeding, suggests that additional treatments, such as surgical evacuation after stabilisation might be needed to change the natural history of intracerebral haemorrhage. The FAST trial subgroup analysis ${ }^{82}$ suggested potential benefit for patients younger than 70 years, with baseline haematoma volume less than $60 \mathrm{~mL}$, baseline intraventricular haemorrhage volume less than $5 \mathrm{~mL}$, and time from onset less than or equal to $2.5 \mathrm{~h}$.

\section{Management of mass-effects causing intracranial hypertension}

Mass-effects resulting from haematomas, oedematous tissue surrounding haematomas, and obstructive hydrocephalus with subsequent herniation are a major cause of death in the first few days after intracerebral haemorrhage. Monitoring of intracranial pressure might identify the risk of neurological deterioration ${ }^{83}$ in patients with impaired consciousness. ${ }^{55}$ Intensive care leading to controlled cerebral perfusion pressure of 50-70 $\mathrm{mm} \mathrm{Hg}$ might improve outcome. ${ }^{83}$ 
Two randomised trials showed no benefit on regional cerebral blood flow, neurological improvement, mortality, and functional outcomes from regular use of intravenous mannitol boluses. ${ }^{84-87}$ Therefore, only short-term use of mannitol in patients with intra-cerebral haemorrhage under special circumstances, such as transtentorial herniation or acute neurological deterioration associated with high intracranial pressure or mass-effect, should be considered. A single-centre observational study suggested that aggressive, timely reversal of transtentorial herniation through the use of hyperventilation and osmotic drugs improved the long-term outcome. ${ }^{74}$

The American Stroke Association (ASA) Stroke Council ${ }^{88}$ recognises the absence of definitive clinical trial evidence in this specialty but recommends monitoring of intracranial pressure in patients treated with osmotic diuretics, cerebrospinal fluid drainage via ventricular catheter, neuromuscular blockade, and hyperventilation. The European Stroke Initiative (EUSI) guidelines ${ }^{54}$ recommend monitoring of intracranial pressure for patients who need mechanical ventilation and recommend treatment in patients who have neurological deterioration related to increasing cerebral oedema on neuroimaging or high intracranial pressure. Both guidelines recommend selective use of mannitol, hypertonic saline, and short-term hyperventilation to maintain cerebral per fusion pressure greater than $70 \mathrm{~mm} \mathrm{Hg}$.

\section{Management of blood pressure}

The acute hypertensive response in intracerebral haemorrhage is characterised by its high prevalence, self-limiting nature, and prognostic significance. ${ }^{89}$ In an analysis of 45330 patients with intracerebral haemorrhage, $75 \%$ had systolic blood pressure greater than 140 $\mathrm{mm} \mathrm{Hg}$ and $20 \%$ greater than $180 \mathrm{~mm} \mathrm{Hg}$ at presentation..$^{90}$ The high blood pressure might be secondary to uncontrolled chronic hypertension, with disruption of central autonomic pathways by intra-cerebral haemorrhage ${ }^{89}$ High blood pressure is associated with haematoma enlargement and poor outcome; ${ }^{37}$ however, an exact cause and effect relation is not proven. ${ }^{34}$ The 1999 ASA guidelines ${ }^{55}$ are based on expert opinion and recommend lowering of blood pressure to keep mean arterial pressure at less than $130 \mathrm{~mm} \mathrm{Hg}$ in patients with a history of hypertension. Patients with intracerebral haemorrhage treated with intravenous infusion of calcium channel blockers consistent with 1999 ASA guidelines within $24 \mathrm{~h}$ of symptom onset tolerated treatment well and had low rates of neurological deterioration and haematoma expansion. ${ }^{36}$ Comparisons suggest that intravenous-bolusbased regimens produce more variable blood-pressure control than do infusion-based regimens of antihypertensive treatment. ${ }^{73}$

The current ASA Stroke Council ${ }^{88}$ guidelines recommend "until ongoing clinical trials of blood pressure intervention for intracerebral haemorrhage are completed, physicians must manage blood pressure on the basis of the present incomplete evidence..." by maintaining systolic blood pressure less than $180 \mathrm{~mm} \mathrm{Hg}$ in the acute period with short half-life intravenous anti-hypertensive drugs. Both guidelines consider more aggressive systolic blood-pressure lowering in the absence of clinical signs of high intracranial pressure ${ }^{88}$ or chronic hypertension. ${ }^{54}$ Recent data suggest a greater therapeutic benefit with more aggressive lowering of blood pressure. ${ }^{91}$ In one observational study, haematomas enlarged in $9 \%$ of patients with systolic blood pressure maintained below $150 \mathrm{~mm} \mathrm{Hg}$ and in $30 \%$ of those with systolic blood pressure maintained at less than $160 \mathrm{~mm} \mathrm{Hg}$ or a higher threshold. ${ }^{91}$ The Antihypertensive Treatment of Acute Cerebral Hemorrhage (ATACH) trial $^{92}$ and the Intensive Blood Pressure Reduction in Acute Cerebral Haemorrhage (INTERACT) trial reported that aggressive reduction of blood pressure to less than $140 \mathrm{~mm}$ $\mathrm{Hg}$ probably decreases the rate of substantial haematoma enlargement ${ }^{93}$ without increasing adverse events. ${ }^{94}$ In subgroup analyses from INTERACT, ${ }^{93}$ patients recruited within $3 \mathrm{~h}$ and those with an initial systolic blood pressure of $181 \mathrm{~mm} \mathrm{Hg}$ or more seemed to have the 
greatest benefit with aggressive lowering of blood pressure. No difference in rates of death and disability at 3 months were seen between patients treated with aggressive and conservative lowering of blood pressure in ATACH or INTERACT studies, although the analyses were limited by small sample sizes. Because the effect on clinical outcome has not been fully assessed, the more conservative targets set in the ASA Stroke Council ${ }^{88}$ and the EUSI guidelines ${ }^{54}$ should be followed. Great caution is advised about lowering blood pressure too aggressively without concomitant management of cerebral perfusion pressure.

\section{Management of intraventricular haemorrhage and hydrocephalus}

Two clinical trials ${ }^{70,81}$ confirmed that intraventricular haemorrhage and hydrocephalus are independent predictors of poor outcome in spontaneous intracerebral haemorrhage. ${ }^{95}$ Impaired flow of cerebrospinal fluid and direct mass-effects of ventricular blood lead to obstructive hydrocephalus. External drainage of cerebrospinal fluid through ventricular catheters reduces intracranial pressure, ${ }^{96}$ but clots in the catheter and infections prevent sustained beneficial effects on hydrocephalus and neurological status in many patients. ${ }^{79,97}$ Shortening the length of external ventricular drainage with early ventriculoperitoneal shunt placement ${ }^{98}$ or lumbar drainage for communicating hydrocephalus ${ }^{99}$ might lower the rate of infections. Substitution of lumbar drainage for external ventricular drainage in patients with communicating hydrocephalus might also lessen the need to change temporary ventricular catheters and to use ventriculoperitoneal shunts. ${ }^{99}$

Intraventricular haemorrhage is a dynamic process that follows intracerebral haemorrhage. In a recent study of fVIIa, $45 \%$ of 374 patients with intracerebral haemorrhage had intraventricular haemorrhage by $24 \mathrm{~h}$ after presentation. ${ }^{100}$ Growth of the intraventricular haemorrhages occurred in $17 \%$ of placebo-treated patients and $10 \%$ of those given fVIIa. Risk factors for growth included a baseline mean arterial pressure of more than $120 \mathrm{~mm} \mathrm{Hg}$, large baseline volume of intracerebral haemorrhage, presence of intraventricular haemorrhage at baseline, shorter time from symptom onset to first CT scan, and lack of treatment with fVIIa. Presence of intraventricular haemorrhage at any time and growth of this haemorrhage increased the likelihood of death or severe disability by 90 days.

To facilitate early and effective clearance of blood in the ventricles, recent efforts have focused on intraventricular use of thrombolytic drugs in patients who have intra ventricular haemorrhage in association with spontaneous intracerebral haemorrhage. ${ }^{77,78,101}$ In a randomised, double-blind, controlled trial, ${ }^{79}$ intra-ventricular thrombolytics given every 12 $\mathrm{h}$ led to faster resolution of intraventricular haemorrhage than did treatment with ventricular drainage alone. Two systematic reviews of clinical studies ${ }^{102,103}$ found a $30-50 \%$ reduction in mortality associated with thrombolytic treatment for intraventricular haemorrhage. Clinical trials have not clearly shown improved neurological outcome in survivors of intraventricular haemorrhage. The Clot Lysis: Evaluating Accelerated Resolution of IVH (CLEAR-IVH) trial is investigating this issue. ${ }^{104}$

Observational studies showed encouraging results for endoscopic removal of intraventricular haemorrhage. ${ }^{105-107}$ In one study, 24 of 25 patients with intra-ventricular haemorrhage and obstructive hydrocephalus had resolution of hydrocephalus after endoscopic evacuation. ${ }^{107}$ In a single-centre, non-randomised comparison study, ${ }^{105}$ endoscopic removal of intraventricular haemorrhage resulted in a higher rate of good recovery at 2 months than did external ventricular drainage alone.

\section{Surgical evacuation}

Surgical evacuation may prevent expansion, decrease mass-effects, block the release of neuropathic products from haematomas, and thus prevent initiation of pathological 
processes. The Surgical Trial in Intracerebral Haemorrhage (STICH) trial ${ }^{70}$ compared early surgery (median time of $20 \mathrm{~h}$ from presentation to surgery) with medical treatment. 1033 patients were randomly assigned to early surgery or initial conservative treatment. At 6 months, early surgery had no benefit compared with initial conservative treatment: $24 \%$ versus $26 \%$ had good recovery or moderate disability after treatment. ${ }^{70}$ The benefits of surgery via open craniotomy can be outweighed by neural damage incurred and recurrence of bleeding, especially in deep lesions. In a subgroup analysis of the STICH trial, surgical treatment of lobar haematomas and haematomas within $1 \mathrm{~cm}$ of the cortical surface were most likely to benefit ${ }^{70,108-110}$ (figure 6). The STICH II trial has started, and will prospectively test for benefits of surgery in lobar intracerebral haemorrhage when clots extend to within $1 \mathrm{~cm}$ of the cortical surface but remain intraparenchymal without spread to the ventricular system. ${ }^{108}$ Another potential indication for surgery is acute neurological worsening. One report ${ }^{111}$ suggested that emergent surgical evacuation could result in functional independence in a quarter of patients if they had not lost upper brainstem reflexes and did not show extensor posturing. Another prospective ran domised study ${ }^{112}$ suggested that the benefit of early surgery is limited to patients presenting with initial Glasgow coma scale scores of 8 or more or intra cerebral haemorrhage volumes of $80 \mathrm{~mL}$ or less.

To limit neural damage and the risk of recurrent bleeding associated with open craniotomy, studies are now focusing on less invasive stereotactic and endoscopic evacuation with the use of thrombolytic drugs. ${ }^{113}$ A randomised trial ${ }^{114}$ showed that stereotactic evacuation of putaminal haematoma was associated with lower mortality and better recovery to functional independence in patients with mildly reduced consciousness. Another trial ${ }^{109}$ randomly assigned 36 patients to stereotactic aspiration after liquefaction with urokinase and 35 to conservative management. Surgery showed a greater haematoma reduction $(18 \mathrm{~mL}$ compared with $7 \mathrm{~mL}$ with conservative management), but no clinical improvement. The ongoing Minimally Invasive Surgery plus Tissue Plasminogen Activator for Intracerebral Hemorrhage Evacuation (MISTIE) ${ }^{108}$ trial is designed to find the best dose of thrombolytics capable of removing $80 \%$ of intracerebral haemorrhage volume by use of stereotactic aspiration followed by catheter-based removal irrigation of intra cerebral haemorrhage with thromboytics.

The ASA Stroke Council ${ }^{88}$ and EUSI guidelines ${ }^{54}$ do not recommend routine evacuation of supratentorial haemorrhage by standard craniotomy within $96 \mathrm{~h}$ of ictus. Both guidelines recommend surgery for patients presenting with lobar haemorrhage within $1 \mathrm{~cm}$ of the surface, particularly for those with good neurological status who are deteriorating clinically. Guidelines acknowledge that operative removal within $12 \mathrm{~h}$, particularly with minimallyinvasive methods, has the most evidence for beneficial effect and could be considered for deep haemorrhages in the presence of mass-effect. ${ }^{54}$ However, guidelines note that very early craniotomy might be associated with an increased risk of recurrent bleeding. ${ }^{115}$

\section{Posterior fossa surgery}

Timely decompression in cerebellar haematomas can lower morbidity and mortality related to compression of the brainstem. In an analysis of the data from a national stroke registry, ${ }^{116}$ patients treated surgically had significantly greater improvement in neurological scores than did those treated medically, independent of age and initial severity of deficits. In most institutions, evidence of neurological deterioration is an indication for surgical evacuation; ${ }^{117}$ although surgical intervention before neurological deterioration might be more beneficial if there is severe fourth ventricular compression. ${ }^{118}$ The best functional results are seen with early craniotomy in patients with a cerebellar haemorrhage who had an initial Glasgow coma scale score of less than 14 or large haemorrhages $(\geq 40 \mathrm{~mL}){ }^{1}$ Endoscopic removal of cerebellar haemorrhage ${ }^{119}$ can also effectively remove the 
haematoma with lower procedure time and a shorter period of cerebrospinal fluid drainage than with craniectomy.

The ASA Stroke Council ${ }^{88}$ and EUSI guidelines ${ }^{54}$ recommend urgent surgery for patients with cerebellar haemorrhages with a relatively good neurological status or haematoma larger than $3 \mathrm{~cm}$ who are deteriorating clinically, or who have brainstem compression or hydrocephalus from ventricular obstruction. Cerebellar haemorrhage is commonly complicated by obstructive hydrocephalus ${ }^{120}$ with delayed but rapidly rising intracranial pressure, which can be treated successfully with external ventricular drainage. ${ }^{121}$ The consequences of longlasting intracranial hypertension with delayed drainage should be avoided by careful monitoring of intracranial pressure and neurological status and use of serial CT scans.

\section{Neuroprotective and seizure treatment}

NXY-059, a free-radical-trapping neuroprotectant, ${ }^{122}$ was investigated in a randomised trial of 607 patients with intracerebral haemorrhage within $6 \mathrm{~h}$ of symptom onset. ${ }^{123}$ Although the use of NXY-059 was associated with slightly less haematoma growth than use of placebo (mean change of $4.5 \mathrm{~mL}$ vs $6.7 \mathrm{~mL}$ ), on comparison of baseline scans to those $72 \mathrm{~h}$ after treatment onset, the drug had no effect on mortality at 3 months, disability, or neurological deficit scores.

$8 \%$ of patient with intracerebral haemorrhage have clinical seizures ${ }^{124}$ within 1 month of symptom onset, associated with lobar location or haematoma enlargement. However, continuous electro encephalographic monitoring in an observational study ${ }^{125}$ showed that $28 \%$ of patients with intracerebral haemorrhage had (predominantly subclinical) seizures within the first $72 \mathrm{~h}$ of admission. Seizures were associated with neurological worsening, an increase in midline shift, and poorer outcomes. In another study of 45 patients with intracerebral haemorrhage, ${ }^{126}$ sub clinical seizures and non-convulsive status epilepticus were detected in $13 \%$ and $9 \%$ of the patients, respectively. Therefore, a low threshold for obtaining electroencephalographic studies and use of anticonvulsants in patients with intracerebral haemorrhage might be advisable. On the basis of risk reduction reported in observational studies, ${ }^{124}$ a 30 -day course of prophylactic anticonvulsants is recommended in patients with lobar haemorrhage or those who develop seizures. ${ }^{54,88}$ Patients who have a seizure more than 2 weeks after intracerebral haemorrhage onset are at greater risk of recurrent seizures than those who do not and might need long-term prophylactic treatment with anticonvulsants.

\section{Management of medical complications}

About $30 \%$ of patients with intracerebral haemorrhage have gastric haemorrhages. Prophylactic $\mathrm{H} 2$ blockers or drugs that can protect the mucosa lower the numbers of such events. ${ }^{127}$ In a randomised trial, ${ }^{127}$ gastric haemorrhages occurred in $23 \%, 11 \%$, and $14 \%$ of patients treated with placebo, ranitidine, and sucralfate, respectively; in-hospital mortality was $28 \%, 11 \%$, and $25 \%$.

In the first 2 weeks, deep-venous thrombosis can be detected by ultrasonography in $40 \%$ of patients. ${ }^{128}$ Patients with severe neurological deficits and high d-dimer concentrations are at highest risk. ${ }^{128}$ The rate of clinical deep-venous thrombosis was $4 \%$ and pulmonary embolism $1 \%$ within 3 months, in a combined analysis of placebo-treated patients in fVIIa trials. ${ }^{129}$ A randomised study ${ }^{130}$ showed that intermittent pneumatic compression decreased the occurrence of asymptomatic deep-venous thromboembolism compared with elastic stockings alone and should be used in all patients. The seventh American College of Chest Physicians panel recommends that a low-dose regimen of sub cutaneous heparin or low- 
molecular-weight heparin can be started on the second day after onset of intracerebral haemorrhage in neurologically stable patients. ${ }^{131} \mathrm{~A}$ small study showed a low incidence of pulmonary embolism without an incremental rate of new intracerebral haemorrhage if lowdose heparin was started on the second day after onset (compared with later intervals). ${ }^{132}$ Once a deep-venous thromboembolism develops, treatment should be given to patients at high risk of pulmonary embolism. Inferior vena-cava filters or a 5-10-day course of fulldose low-molecular-weight heparin followed by 3 months of lower-dose low-molecularweight heparin are possible alternatives to warfarin. ${ }^{133}$

$10 \%$ of intensively treated patients with intracerebral haemorrhage need tracheostomies, and early use might reduce the risk of aspiration and long-term mechanical ventilation. ${ }^{134}$ Recent guidelines have placed emphasis on control of hyperthermia and hyperglycaemia with antipyretic medication and possibly insulin infusion in the acute period of intracerebral haemorrhage. ${ }^{54,88}$

\section{Intracerebral haemorrhage related to use of oral anticoagulants}

A population based study ${ }^{135}$ reported that intracerebral haemorrhage associated with oral anticoagulant use comprised 5\% of all intracerebral haemorrhages in 1988, 9\% in 1993-94, and $17 \%$ in 1999, with the observed increase presumably due to increasing prevalence of atrial fibrillation and higher rates of warfarin use. ${ }^{11}$ Although most cases associated with oral anticoagulant use occur when international normalised ratios are within the therapeutic range, higher ratios increase the risk. ${ }^{136}$ Advancing age and cerebral amyloid angiopathy are also important contributory factors to intracerebral haemorrhage associated with oral anticoagulant use. ${ }^{11,137}$ In a multicentre study, a progressive neurological deterioration during the first 24-48 $\mathrm{h}$ was seen in almost half of patients with intracerebral haemorrhage associated with oral anticoagulant use and a high mortality (64\%) by 6 months. ${ }^{138}$ The high mortality in these patients was mediated by a high rate of early and delayed haematoma enlargement ${ }^{139}$ which was commonly associated with persistently high international normalised ratio after admission. ${ }^{140,141}$

Rapid reversal of systemic anticoagulation with a combination of intravenous vitamin K, prothrombin complex concentrates, or fresh frozen plasma and fVIIa is recommended preferably within $2 \mathrm{~h}$ of onset. ${ }^{11,142,143}$ Prothrombin complex concentrates or fVIIa can achieve rapid reversal although the international normalised ratio might increase in subsequent hours owing to the short half-lives of these drugs requiring follow-up monitoring. In a single-centre review, ${ }^{141}$ haematomas enlarged in $19 \%$ of patients given prothrombin complex concentrates, $33 \%$ given fresh frozen plasma, and $50 \%$ given vitamin $\mathrm{K}$. An early reversal of international normalised ratio (within $2 \mathrm{~h}$ ) was achieved in $84 \%$ with prothrombin complex concentrates, $39 \%$ with fresh frozen plasma, and $0 \%$ with vitamin $\mathrm{K}$. International normalised ratio reversal to less than 1.4 within $2 \mathrm{~h}$ was associated with low rates of haematoma enlargement. A retrospective study ${ }^{144}$ compared the outcomes of neurosurgical patients with intracranial haemorrhage treated with fresh frozen plasma and fVIIa and those managed with fresh frozen plasma alone. International normalised ratios returned to normal over a mean period of $7 \mathrm{~h}$ in those given fVIIa and $47 \mathrm{~h}$ in those who were not. More patients treated with fVIIa had good functional outcome than did those who received only fresh frozen plasma. Rapid reversal of international normalised ratios also enables urgent surgical evacuations in patients who are deteriorating neurologically with intracerebral haemorrhage related to oral anticoagulant use. One study ${ }^{145}$ reported a high rate $(65 \%)$ of favourable outcomes in patients with prominent midline shift (with or without uncal herniation) who had emergent surgical evacuation after reversal. 
The clinical issue regarding reinstitution of anticoagulation is controversial. Two studies concluded that antithrombotic drugs should be avoided where possible in patients with acute intracerebral haemorrhage. ${ }^{146,147}$ A subgroup at high risk of thromboembolic stroke and low risk of recurrence might benefit from long-term anticoagulation or aspirin. Both the ASA Stroke Council ${ }^{88}$ and the EUSI guidelines ${ }^{54}$ recommend that warfarin can be started again in patients at a very high risk of thromboembolism at 7-14 days after onset of the original intracerebral haemorrhage. ${ }^{148,149}$

\section{Future directions}

Clinical evidence suggests the importance of three management tasks in intracerebral haemorrhage: stopping the bleeding, ${ }^{81}$ removing the clot, ${ }^{70}$ and controlling cerebral perfusion pressure. ${ }^{92}$ The precision needed to achieve these goals and the degree of benefit attributable to each clinical goal would be precisely defined when the results of trials in progress become available. An NIH workshop ${ }^{150}$ identified the importance of animal models of intracerebral haemorrhage and of human pathology studies. Use of real-time, high-field MRI with three-dimensional imaging and high-resolution tissue probes is another priority. Trials of acute blood-pressure treatment and coagulopathy reversal are also medical priorities. And trials of minimally invasive surgical techniques including mechanical and pharmacological adjuncts are surgical priorities. The STICH II trial should determine the benefit of craniotomy for lobar haemorrhage. A better understanding of methodological challenges, including establishment of research networks and multispecialty approaches, is also needed. ${ }^{150}$ New information created in each of these areas should add substantially to our knowledge about the effcacy of treatment for intracerebral haemorrhage.

\section{Acknowledgments}

AIQ has received funding from National Institutes of Health RO-1-NS44976-01A2 (medication provided by ESP Pharma), American Heart Association Established Investigator Award 0840053N, and Minnesota Medical Foundation (Minneapolis, MN, USA). ADM is the director of the Newcastle Neurosurgery Foundation, and has received honoraria for attending Advisory Committee Meetings for Codman and for Novo Nordisk. DFH receives funding through the US Food and Drug Administration orphan-drugs programme grant 5RO1-FD 001693, National Institute of Neurological Disorders and Stroke (NINDS) planning grant, 1R34-NS056638, MISITIE: NINDS, 1R01-NS 046309, Jeffrey and Harriet Legum professorship, Genentech, sponsored research agreement; he also has disavowed interest in this patent (Johns Hopkins University use patent application \# 10/509,694) and has received an honorarium from Novo Nordisk.

\section{References}

1. Qureshi AI, Tuhrim S, Broderick JP, Batjer HH, Hondo H, Hanley DF. Spontaneous intracerebral hemorrhage. N Engl J Med. 2001; 344:1450-60. [PubMed: 11346811]

2. Labovitz DL, Halim A, Boden-Albala B, Hauser WA, Sacco RL. The incidence of deep and lobar intracerebral hemorrhage in whites, blacks, and hispanics. Neurology. 2005; 65:518-22. [PubMed: 16116109]

3. Sudlow CL, Warlow CP. Comparable studies of the incidence of stroke and its pathological types: results from an international collaboration. Stroke. 1997; 28:491-99. [PubMed: 9056601]

4. American Heart Organization. [accessed Nov 21, 2007] International cardiovascular disease statistics: cardiovascular disease (CVD).

http://www.americanheart.org/downloadable/heart/1140811583642InternationalCVD.pdf

5. Qureshi AI, Suri MFK, Nasar A, et al. Changes in cost and outcome among US patients with stroke hospitalized in 1990 to 1991 and those hospitalized in 2000 to 2001. Stroke. 2007; 38:2180-84. [PubMed: 17525400]

6. Feigin VL, Lawes CMM, Bennett DA, Anderson CS. Stroke epidemiology: a review of populationbased studies of incidence, prevalence, and case-fatality in the late 20th century. Lancet Neurol. 2003; 2:43-53. [PubMed: 12849300] 
7. Morgenstern LB, Spears WD. A triethnic comparison of intracerebral hemorrhage mortality in Texas. Ann Neurol. 1997; 42:919-23. [PubMed: 9403485]

8. Kubo M, Kiyohara Y, Kato I, et al. Trends in the incidence, mortality, and survival rate of cardiovascular disease in a Japanese community: the Hisayama study. Stroke. 2003; 34:2349-54. [PubMed: 12958323]

9. Jiang B, Wang WZ, Chen H, et al. Incidence and trends of stroke and its subtypes in China: results from three large cities. Stroke. 2006; 37:63-68. [PubMed: 16306469]

10. Rothwell PM, Coull AJ, Giles MF, et al. Change in stroke incidence, mortality, case-fatality, severity, and risk factors in Oxfordshire, UK from 1981 to 2004 (Oxford Vascular Study). Lancet. 2004; 363:1925-33. [PubMed: 15194251]

11. Steiner T, Rosand J, Diringer M. Intracerebral hemorrhage associated with oral anticoagulant therapy: current practices and unresolved questions. Stroke. 2006; 37:256-62. [PubMed: 16339459]

12. Takebayashi S, Kaneko M. Electron microscopic studies of ruptured arteries in hypertensive intracerebral hemorrhage. Stroke. 1983; 14:28-36. [PubMed: 6823683]

13. Mizutani T, Kojima H, Miki Y. Arterial dissections of penetrating cerebral arteries causing hypertension-induced cerebral hemorrhage. J Neurosurg. 2000; 93:859-62. [PubMed: 11059669]

14. Rosand J, Hylek EM, O’Donnell HC, Greenberg SM. Warfarin-associated hemorrhage and cerebral amyloid angiopathy: a genetic and pathologic study. Neurology. 2000; 55:947-51. [PubMed: 11061249]

15. Rost NS, Greenberg SM, Rosand J. The genetic architecture of intracerebral hemorrhage. Stroke. 2008; 39:2166-73. [PubMed: 18467649]

16. Hart RG. What causes intracerebral hemorrhage during warfarin therapy? Neurology. 2000; 55:907-08. [PubMed: 11061242]

17. Smith EE, Gurol ME, Eng JA, et al. White matter lesions, cognition, and recurrent hemorrhage in lobar intracerebral hemorrhage. Neurology. 2004; 63:1606-12. [PubMed: 15534243]

18. Qureshi AI, Suri MF, Ostrow PT, et al. Apoptosis as a form of cell death in intracerebral hemorrhage. Neurosurgery. 2003; 52:1041-47. [PubMed: 12699545]

19. Qureshi AI, Ali Z, Suri MF, et al. Extracellular glutamate and other amino acids in experimental intracerebral hemorrhage: an in vivo microdialysis study. Crit Care Med. 2003; 31:1482-89. [PubMed: 12771622]

20. Lusardi TA, Wolf JA, Putt ME, Smith DH, Meaney DF. Effect of acute calcium influx after mechanical stretch injury in vitro on the viability of hippocampal neurons. J Neurotrauma. 2004; 21:61-72. [PubMed: 14987466]

21. Graham DI, McIntosh TK, Maxwell WL, Nicoll JA. Recent advances in neurotrauma. J Neuropathol Exp Neurol. 2000; 59:641-51. [PubMed: 10952055]

22. Nakamura T, Xi G, Park JW, Hua Y, Hoff JT, Keep RF. Holo-transferrin and thrombin can interact to cause brain damage. Stroke. 2005; 36:348-52. [PubMed: 15637325]

23. Xi G, Keep RF, Hoff JT. Mechanisms of brain injury after intracerebral haemorrhage. Lancet Neurol. 2006; 5:53-63. [PubMed: 16361023]

24. Nakamura T, Keep RF, Hua Y, Nagao S, Hoff JT, Xi G. Iron-induced oxidative brain injury after experimental intracerebral hemorrhage. Acta Neurochir Suppl. 2006; 96:194-48. [PubMed: 16671453]

25. Wagner KR, Packard BA, Hall CL, et al. Protein oxidation and heme oxygenase-1 induction in porcine white matter following intracerebral infusions of whole blood or plasma. Dev Neurosci. 2002; 24:154-60. [PubMed: 12401953]

26. Wang J, Tsirka SE. Tuftsin fragment $1-3$ is beneficial when delivered after the induction of intracerebral hemorrhage. Stroke. 2005; 36:613-48. [PubMed: 15692122]

27. Alvarez-Sabin J, Delgado P, Abilleira S, et al. Temporal profile of matrix metalloproteinases and their inhibitors after spontaneous intracerebral hemorrhage: relationship to clinical and radiological outcome. Stroke. 2004; 35:1316-22. [PubMed: 15087562]

28. Aronowski J, Hall CE. New horizons for primary intracerebral hemorrhage treatment: experience from preclinical studies. Neurol Res. 2005; 27:268-79. [PubMed: 15845210] 
29. Hua Y, Wu J, Keep RF, Nakamura T, Hoff JT, Xi G. Tumor necrosis factor-alpha increases in the brain after intracerebral hemorrhage and thrombin stimulation. Neurosurgery. 2006; 58:542-50. [PubMed: 16528196]

30. Gong C, Boulis N, Qian J, Turner DE, Hoff JT, Keep RF. Intracerebral hemorrhage-induced neuronal death. Neurosurgery. 2001; 48:875-82. [PubMed: 11322448]

31. Matz PG, Lewen A, Chan PH. Neuronal, but not microglial, accumulation of extravasated serum proteins after intracerebral hemolysate exposure is accompanied by cytochrome c release and DNA fragmentation. J Cereb Blood Flow Metab. 2001; 21:921-28. [PubMed: 11487727]

32. Yang S, Nakamura T, Hua Y, et al. The role of complement C3 in intracerebral hemorrhageinduced brain injury. J Cereb Blood Flow Metab. 2006; 26:1490-95. [PubMed: 16552422]

33. Fujii Y, Takeuchi S, Harada A, Abe H, Sasaki O, Tanaka R. Hemostatic activation in spontaneous intracerebral hemorrhage. Stroke. 2001; 32:883-90. [PubMed: 11283387]

34. Broderick JP, Diringer MN, Hill MD, et al. Determinants of intracerebral hemorrhage growth: an exploratory analysis. Stroke. 2007; 38:1072-75. [PubMed: 17290026]

35. Davis SM, Broderick J, Hennerici M, et al. Hematoma growth is a determinant of mortality and poor outcome after intracerebral hemorrhage. Neurology. 2006; 66:1175-81. [PubMed: 16636233]

36. Qureshi AI, Harris-Lane P, Kirmani JF, et al. Treatment of acute hypertension in patients with intracerebral hemorrhage using American Heart Association guidelines. Crit Care Med. 2006; 34:1975-80. [PubMed: 16641615]

37. Kazui SMK, Sawada T, Yamaguchi T. Predisposing factors to enlargement of spontaneous intracerebral hematoma. Stroke. 1997; 28:2370-75. [PubMed: 9412616]

38. Gebel JM Jr, Jauch EC, Brott TG, et al. Natural history of perihematomal edema in patients with hyperacute spontaneous intracerebral hemorrhage. Stroke. 2002; 33:2631-35. [PubMed: 12411653]

39. Inaji M, Tomita H, Tone O, Tamaki M, Suzuki R, Ohno K. Chronological changes of perihematomal edema of human intracerebral hematoma. Acta Neurochir Suppl. 2003; 86:445-48. [PubMed: 14753483]

40. Butcher KS, Baird T, MacGregor L, Desmond P, Tress B, Davis S. Perihematomal edema in primary intracerebral hemorrhage is plasma derived. Stroke. 2004; 35:1879-85. [PubMed: 15178826]

41. Gebel JM Jr, Jauch EC, Brott TG, et al. Relative edema volume is a predictor of outcome in patients with hyperacute spontaneous intracerebral hemorrhage. Stroke. 2002; 33:2636-41. [PubMed: 12411654]

42. Qureshi AI, Hanel RA, Kirmani JF, Yahia AM, Hopkins LN. Cerebral blood flow changes associated with intracerebral hemorrhage. Neurosurg Clin N Am. 2002; 13:355-70. [PubMed: 12486925]

43. Siddique MS, Fernandes HM, Wooldridge TD, Fenwick JD, Slomka P, Mendelow AD. Reversible ischemia around intracerebral hemorrhage: a single-photon emission computerized tomography study. J Neurosurg. 2002; 96:736-41. [PubMed: 11990815]

44. Kim-Han JS, Kopp SJ, Dugan LL, Diringer MN. Perihematomal mitochondrial dysfunction after intracerebral hemorrhage. Stroke. 2006; 37:2457-62. [PubMed: 16960094]

45. Carhuapoma JR, Wang PY, Beauchamp NJ, Keyl PM, Hanley DF, Barker PB. Diffusion-weighted MRI and proton MR spectroscopic imaging in the study of secondary neuronal injury after intracerebral hemorrhage. Stroke. 2000; 31:726-32. [PubMed: 10700511]

46. Zazulia AR, Diringer MN, Videen TO, et al. Hypoperfusion without ischemia surrounding acute intracerebral hemorrhage. J Cereb Blood Flow Metab. 2001; 21:804-10. [PubMed: 11435792]

47. Schellinger PD, Fiebach JB, Hoffmann K, et al. Stroke MRI in intracerebral hemorrhage: is there a perihemorrhagic penumbra? Stroke. 2003; 34:1674-79. [PubMed: 12805502]

48. Orakcioglu B, Fiebach JB, Steiner T, et al. Evolution of early perihemorrhagic changes-ischemia vs edema: an MRI study in rats. Exp Neurol. 2005; 193:369-76. [PubMed: 15869939]

49. Qureshi AI, Wilson DA, Hanley DF, Traystman RJ. No evidence for an ischemic penumbra in massive experimental intracerebral hemorrhage. Neurology. 1999; 52:266-72. [PubMed: 9932942] 
50. Fiebach JB, Schellinger PD, Gass A, et al. Stroke magnetic resonance imaging is accurate in hyperacute intracerebral hemorrhage: a multicenter study on the validity of stroke imaging. Stroke. 2004; 35:502-06. [PubMed: 14739410]

51. Kidwell CS, Chalela JA, Saver JL, et al. Comparison of MRI and CT for detection of acute intracerebral hemorrhage. JAMA. 2004; 292:1823-30. [PubMed: 15494579]

52. Becker KJ, Baxter AB, Bybee HM, Tirschwell DL, Abouelsaad T, Cohen WA. Extravasation of radiographic contrast is an independent predictor of death in primary intracerebral hemorrhage. Stroke. 1999; 30:2025-32. [PubMed: 10512902]

53. Goldstein JN, Fazen LE, Snider R, et al. Contrast extravasation on CT angiography predicts hematoma expansion in intracerebral hemorrhage. Neurology. 2007; 68:889-94. [PubMed: 17372123]

54. Steiner T, Katse M, Forsting M, et al. Recommendations for the management of intracranial haemorrhage_-part I: spontaneous intracerebral haemorrhage. Cerebrovasc Dis. 2006; 22:294 316. [PubMed: 16926557]

55. Broderick JP, Adams HP Jr, Barsan W, et al. Guidelines for the management of spontaneous intracerebral hemorrhage: a statement for healthcare professionals from a special writing group of the Stroke Council, American Heart Association. Stroke. 1999; 30:905-15. [PubMed: 10187901]

56. Moon J-S, Janjua N, Ahmed S, et al. Prehospital neurologic deterioration in patients with intracerebral hemorrhage. Crit Care Med. 2008; 36:172-75. [PubMed: 18007267]

57. Leira R, Davalos A, Silva Y, et al. Early neurologic deterioration in intracerebral hemorrhage: predictors and associated factors. Neurology. 2004; 63:461-67. [PubMed: 15304576]

58. Mayer SA, Sacco RL, Shi T, Mohr JP. Neurologic deterioration in noncomatose patients with supratentorial intracerebral hemorrhage. Neurology. 1994; 44:1379-84. [PubMed: 8058133]

59. Hemphill JC 3rd, Bonovich DC, Besmertis L, Manley GT, Johnston SC. The ICH score: a simple, reliable grading scale for intracerebral hemorrhage. Stroke. 2001; 32:891-97. [PubMed: 11283388]

60. Weimar C, Weber C, Wagner M, et al. Management patterns and health care use after intracerebral hemorrhage. a cost-of-illness study from a societal perspective in Germany. Cerebrovasc Dis. 2003; 15:29-36. [PubMed: 12499708]

61. Flaherty ML, Haverbusch M, Sekar P, et al. Long-term mortality after intracerebral hemorrhage. Neurology. 2006; 66:1182-86. [PubMed: 16636234]

62. Fogelholm R, Murros K, Rissanen A, Avikainen S. Long term survival after primary intracerebral haemorrhage: a retrospective population based study. J Neurol Neurosurg Psychiatry. 2005; 76:1534-38. [PubMed: 16227546]

63. Bailey RD, Hart RG, Benavente O, Pearce LA. Recurrent brain hemorrhage is more frequent than ischemic stroke after intracranial hemorrhage. Neurology. 2001; 56:773-77. [PubMed: 11274313]

64. Chen YW, Gurol ME, Rosand J, et al. Progression of white matter lesions and hemorrhages in cerebral amyloid angiopathy. Neurology. 2006; 67:83-87. [PubMed: 16832082]

65. PROGRESS Collaborative Group. Randomised trial of a perindopril-based blood-pressurelowering regimen among 6105 individuals with previous stroke or transient ischaemic attack. Lancet. 2001; 358:1033-41. [PubMed: 11589932]

66. Hachinski V. Vascular behavioral and cognitive disorders. Stroke. 2003; 34:2775. [PubMed: 14631076]

67. Zurasky JA, Aiyagari V, Zazulia AR, Shackelford A, Diringer MN. Early mortality following spontaneous intracerebral hemorrhage. Neurology. 2005; 64:725-27. [PubMed: 15728302]

68. Hemphill JC 3rd, Newman J, Zhao S, Johnston SC. Hospital usage of early do-not-resuscitate orders and outcome after intracerebral hemorrhage. Stroke. 2004; 35:1130-34. [PubMed: 15044768]

69. Diringer MN, Edwards DF. Admission to a neurologic/neurosurgical intensive care unit is associated with reduced mortality rate after intracerebral hemorrhage. Crit Care Med. 2001; 29:635-40. [PubMed: 11373434]

70. Mendelow AD, Gregson BA, Fernandes HM, et al. Early surgery versus initial conservative treatment in patients with spontaneous supratentorial intracerebral haematomas in the International 
Surgical Trial in Intracerebral Haemorrhage (STICH): a randomised trial. Lancet. 2005; 365:38797. [PubMed: 15680453]

71. Mayer SA, Brun NC, Begtrup K, et al. Efficacy and safety of recombinant activated factor VII for acute intracerebral hemorrhage. N Engl J Med. 2008; 358:2127-37. [PubMed: 18480205]

72. Tuhrim S. Intracerebral hemorrhage-improving outcome by reducing volume? N Engl J Med. 2008; 358:2174-76. [PubMed: 18480212]

73. Qureshi AI, Mohammad YM, Yahia AM, et al. A prospective multicenter study to evaluate the feasibility and safety of aggressive antihypertensive treatment in patients with acute intracerebral hemorrhage. J Intensive Care Med. 2005; 20:34-42. [PubMed: 15665258]

74. Qureshi AI, Geocadin RG, Suarez JI, Ulatowski JA. Long-term outcome after medical reversal of transtentorial herniation in patients with supratentorial mass lesions. Crit Care Med. 2000; 28:1556-64. [PubMed: 10834711]

75. Goldstein JN, Thomas SH, Frontiero V, et al. Timing of fresh frozen plasma administration and rapid correction of coagulopathy in warfarin-related intracerebral hemorrhage. Stroke. 2006; 37:151-55. [PubMed: 16306465]

76. Gujjar AR, Deibert E, Manno EM, Duff S, Diringer MN. Mechanical ventilation for ischemic stroke and intracerebral hemorrhage: indications, timing, and outcome. Neurology. 1998; 51:44751. [PubMed: 9710017]

77. Naff NJ, Tuhrim S. Intraventricular hemorrhage in adults: complications and treatment. New Horizons. 1997; 5:359-63. [PubMed: 9433988]

78. Naff NJ, Carhuapoma JR, Williams MA, et al. Treatment of intraventricular hemorrhage with urokinase: effects on 30-day survival. Stroke. 2000; 31:841-47. [PubMed: 10753985]

79. Naff NJ, Hanley DF, Keyl PM, et al. Intraventricular thrombolysis speeds blood clot resolution: results of a pilot, prospective, randomized, double-blind, controlled trial. Neurosurgery. 2004; 54:577-83. [PubMed: 15028130]

80. Qureshi AI, Safdar K, Weil J, et al. Predictors of early deterioration and mortality in black Americans with spontaneous intracerebral hemorrhage. Stroke. 1995; 26:1764-67. [PubMed: 7570722]

81. Mayer SA, Brun NC, Begtrup K, et al. Recombinant activated factor VII for acute intracerebral hemorrhage. N Engl J Med. 2005; 352:777-85. [PubMed: 15728810]

82. Mayer SA, Davis SM, Begtrup K, et al. Subgroup analysis in the FAST trial: a subset of intracerebral hemorrhage patients that benefit from recombinant activated factor VII. Stroke. 2008; 39:528.

83. Fernandes HM, Siddique S, Banister K, et al. Continuous monitoring of ICP and CPP following ICH and its relationship to clinical, radiological and surgical parameters. Acta Neurochir Suppl. 2000; 76:463-66. [PubMed: 11450068]

84. Misra UK, Kalita J, Ranjan P, Mandal SK. Mannitol in intracerebral hemorrhage: a randomized controlled study. J Neurol Sci. 2005; 234:41-45. [PubMed: 15936036]

85. Kalita J, Misra UK, Ranjan P, Pradhan PK, Das BK. Effect of mannitol on regional cerebral blood flow in patients with intracerebral hemorrhage. J Neurol Sci. 2004; 224:19-22. [PubMed: 15450766]

86. Sansing LH, Kaznatcheeva EA, Perkins CJ, Komaroff E, Gutman FB, Newman GC. Edema after intracerebral hemorrhage: correlations with coagulation parameters and treatment. J Neurosurg. 2003; 98:985-92. [PubMed: 12744358]

87. Dziedzic T, Szczudlik A, Klimkowicz A, Rog TM, Slowik A. Is mannitol safe for patients with intracerebral hemorrhages? Renal considerations. Clin Neurol Neurosurg. 2003; 105:87-89. [PubMed: 12691796]

88. Broderick J, Connolly S, Feldmann E, et al. Guidelines for the management of spontaneous intracerebral hemorrhage in adults: 2007 update: a guideline from the American Heart Association/American Stroke Association Stroke Council, High Blood Pressure Research Council, and the Quality of Care and Outcomes in Research Interdisciplinary Working Group. Stroke. 2007; 38:2001-23. [PubMed: 17478736]

89. Qureshi AI. Acute hypertensive response in patients with stroke: pathophysiology and management. Circulation. 2008; 118:176-87. [PubMed: 18606927] 
90. Qureshi AI, Ezzeddine MA, Nasar A, et al. Prevalence of elevated blood pressure in 563,704 adult patients with stroke presenting to the ED in the United States. Am J Emerg Med. 2007; 25:32-38. [PubMed: 17157679]

91. Ohwaki K, Yano E, Nagashima H, Hirata M, Nakagomi T, Tamura A. Blood pressure management in acute intracerebral hemorrhage: relationship between elevated blood pressure and hematoma enlargement. Stroke. 2004; 35:1364-67. [PubMed: 15118169]

92. Qureshi AI. Antihypertensive treatment of acute cerebral hemorrhage (ATACH): rationale and design. Neurocrit Care. 2007; 6:56-66. [PubMed: 17356194]

93. Anderson CS, Huang Y, Wang G, et al. Intensive blood pressure reduction in acute cerebral haemorrhage trial (INTERACT): a pilot randomised trial. Lancet Neurol. 2008; 7:391-99. [PubMed: 18396107]

94. Qureshi, AI. Antihypertensive Treatment of Acute Cerebral Hemorrhage (ATACH) trial: International Stroke Conference; New Orleans, LA. Feb 20-22, 2008;

95. Bhattathiri PS, Gregson B, Prasad KS, Mendelow AD. Intraventricular hemorrhage and hydrocephalus after spontaneous intracerebral hemorrhage: results from the STICH trial. Acta Neurochir Suppl. 2006; 96:65-68. [PubMed: 16671427]

96. Ohwaki K, Yano E, Nagashima H, Hirata M, Nakagomi T, Tamura A. Surgery for patients with severe supratentorial intracerebral hemorrhage. Neurocrit Care. 2006; 5:15-20. [PubMed: 16960289]

97. Hanley DF. Intraventricular hemorrhage and ICH outcomes: severity factor and treatment target. Stroke. 2009 published online Feb 26. 10.1161/STROKEAHA.108.535419

98. Yilmazlar S, Abas F, Korfali E. Comparison of ventricular drainage in poor grade patients after intracranial hemorrhage. Neurol Res. 2005; 27:653-56. [PubMed: 16157019]

99. Huttner HB, Nagel S, Tognoni E, et al. Intracerebral hemorrhage with severe ventricular involvement: lumbar drainage for communicating hydrocephalus. Stroke. 2007; 38:183-87. [PubMed: 17122427]

100. Steiner T, Diringer MN, Schneider D, et al. Dynamics of intraventricular hemorrhage in patients with spontaneous intracerebral hemorrhage: risk factors, clinical impact, and effect of hemostatic therapy with recombinant activated factor VII. Neurosurgery. 2006; 59:767-73. [PubMed: 17038942]

101. Huttner HB, Tognoni E, Bardutzky J, et al. Influence of intraventricular fibrinolytic therapy with rt-PA on the long-term outcome of treated patients with spontaneous basal ganglia hemorrhage: a case-control study. Eur J Neurol. 2008; 15:342-49. [PubMed: 18312407]

102. Andrews CO, Engelhard HH. Fibrinolytic therapy in intraventricular hemorrhage. Ann Pharmacother. 2001; 35:1435-48. [PubMed: 11724097]

103. Nieuwkamp DJ, de Gans K, Rinkel GJ, Algra A. Treatment and outcome of severe intraventricular extension in patients with subarachnoid or intracerebral hemorrhage: a systematic review of the literature. J Neurol. 2000; 247:117-21. [PubMed: 10751114]

104. Nyquist P, Hanley DF. The use of intraventricular thrombolytics in intraventricular hemorrhage. J Neurol Sci. 2007; 261:84-88. [PubMed: 17553525]

105. Zhang Z, Li X, Liu Y, Shao Y, Xu S, Yang Y. Application of neuroendoscopy in the treatment of intraventricular hemorrhage. Cerebrovasc Dis. 2007; 24:91-96. [PubMed: 17519550]

106. Longatti PL, Martinuzzi A, Fiorindi A, Maistrello L, Carteri A. Neuroendoscopic management of intraventricular hemorrhage. Stroke. 2004; 35:e35-38. [PubMed: 14739413]

107. Yadav YR, Mukerji G, Shenoy R, Basoor A, Jain G, Nelson A. Endoscopic management of hypertensive intraventricular haemorrhage with obstructive hydrocephalus. BMC Neurol. 2007; 7:1. [PubMed: 17204141]

108. Mendelow AD, Unterberg A. Surgical treatment of intracerebral haemorrhage. Curr Opin Crit Care. 2007; 13:169-74. [PubMed: 17327738]

109. Teernstra OP, Evers SM, Lodder J, Leffers P, Franke CL, Blaauw G. Stereotactic treatment of intracerebral hematoma by means of a plasminogen activator: a multicenter randomized controlled trial (SICHPA). Stroke. 2003; 34:968-74. [PubMed: 12649510] 
110. Auer LM, Deinsberger W, Niederkorn K, et al. Endoscopic surgery versus medical treatment for spontaneous intracerebral hematoma: a randomized study. J Neurosurg. 1989; 70:530-35. [PubMed: 2926492]

111. Rabinstein AA, Atkinson JL, Wijdicks EFM. Emergency craniotomy in patients worsening due to expanded cerebral hematoma: to what purpose? Neurology. 2002; 58:1367-72. [PubMed: 12011282]

112. Pantazis G, Tsitsopoulos P, Mihas C, Katsiva V, Stavrianos V, Zymaris S. Early surgical treatment vs conservative management for spontaneous supratentorial intracerebral hematomas: a prospective randomized study. Surg Neurol. 2006; 66:492-501. [PubMed: 17084196]

113. Broderick JP. The STICH trial: what does it tell us and where do we go from here? Stroke. 2005; 36:1619-20. [PubMed: 15947257]

114. Hattori N, Katayama Y, Maya Y, Gatherer A. Impact of stereotactic hematoma evacuation on activities of daily living during the chronic period following spontaneous putaminal hemorrhage: a randomized study. J Neurosurg. 2004; 101:417-20. [PubMed: 15352598]

115. Morgenstern LB, Demchuk AM, Kim DH, Frankowski RF, Grotta JC. Rebleeding leads to poor outcome in ultra-early craniotomy for intracerebral hemorrhage. Neurology. 2001; 56:1294-99. [PubMed: 11376176]

116. Wang CX, Shuaib A. Neuroprotective effects of free radical scavengers in stroke. Drugs Aging. 2007; 24:537-46. [PubMed: 17658905]

117. Lyden PD, Shuaib A, Lees KR, et al. Safety and tolerability of NXY-059 for acute intracerebral hemorrhage: the CHANT Trial. Stroke. 2007; 38:2262-69. [PubMed: 17569876]

118. Morioka J, Fujii M, Kato S, et al. Surgery for spontaneous intracerebral hemorrhage has greater remedial value than conservative therapy. Surg Neurol. 2006; 65:67-72. [PubMed: 16378863]

119. Wijdicks EF, St Louis EK, Atkinson JD, Li H. Clinician's biases toward surgery in cerebellar hematomas: an analysis of decision-making in 94 patients. Cerebrovasc Dis. 2000; 10:93-96. [PubMed: 10686446]

120. Kirollos RW, Tyagi AK, Ross SA, van Hille PT, Marks PV. Management of spontaneous cerebellar hematomas: a prospective treatment protocol. Neurosurgery. 2001; 49:1378-86. [PubMed: 11846937]

121. Yamamoto T, Nakao Y, Mori K, Maeda M. Endoscopic hematoma evacuation for hypertensive cerebellar hemorrhage. Minim Invasive Neurosurg. 2006; 49:173-78. [PubMed: 16921459]

122. St Louis EK, Wijdicks EF, Li H. Predicting neurologic deterioration in patients with cerebellar hematomas. Neurology. 1998; 51:1364-69. [PubMed: 9818861]

123. Sumer MM, Acikgoz B, Akpinar G. External ventricular drainage for acute obstructive hydrocephalus developing following spontaneous intracerebral haemorrhages. Neurol Sci. 2002; 23:29-33. [PubMed: 12111618]

124. Passero S, Rocchi R, Rossi S, Ulivelli M, Vatti G. Seizures after spontaneous supratentorial intracerebral hemorrhage. Epilepsia. 2002; 43:1175-80. [PubMed: 12366733]

125. Vespa PM, O'Phelan K, Shah M, et al. Acute seizures after intracerebral hemorrhage: a factor in progressive midline shift and outcome. Neurology. 2003; 60:1441-46. [PubMed: 12743228]

126. Claassen J, Mayer SA, Kowalski RG, Emerson RG, Hirsch LJ. Detection of electrographic seizures with continuous EEG monitoring in critically ill patients. Neurology. 2004; 62:1743-48. [PubMed: 15159471]

127. Misra UK, Kalita J, Pandey S, Mandal SK, Srivastava M. A randomized placebo controlled trial of ranitidine versus sucralfate in patients with spontaneous intracerebral hemorrhage for prevention of gastric hemorrhage. J Neurol Sci. 2005; 239:5-10. [PubMed: 16182311]

128. Ogata T, Yasaka M, Wakugawa Y, Inoue T, Ibayashi S, Okada Y. Deep venous thrombosis after acute intracerebral hemorrhage. J Neurol Sci. 2008; 272:83-86. [PubMed: 18555486]

129. Christensen MC, Dawson J, Vincent C. Risk of thromboembolic complications after intracerebral hemorrhage according to ethnicity. Adv Ther. 2008; 25:831-41. [PubMed: 18777016]

130. Lacut K, Bressollette L, Le Gal G, et al. Prevention of venous thrombosis in patients with acute intracerebral hemorrhage. Neurology. 2005; 65:865-69. [PubMed: 16186525] 
131. Albers GW, Amarenco P, Easton JD, Sacco RL, Teal P. Antithrombotic and thrombolytic therapy for ischemic stroke: the seventh ACCP Conference on Antithrombotic and Thrombolytic Therapy. Chest. 2004; 126 (3 suppl):483-512S.

132. Boeer A, Voth E, Henze T, Prange HW. Early heparin therapy in patients with spontaneous intracerebral haemorrhage. J Neurol Neurosurg Psychiatry. 1991; 54:466-67. [PubMed: 1865215]

133. Kelly J, Hunt BJ, Lewis RR, Rudd A. Anticoagulation or inferior vena cava filter placement for patients with primary intracerebral hemorrhage developing venous thromboembolism? Stroke. 2003; 34:2999-3005. [PubMed: 14615615]

134. Huttner HB, Kohrmann M, Berger C, Georgiadis D, Schwab S. Predictive factors for tracheostomy in neurocritical care patients with spontaneous supratentorial hemorrhage. Cerebrovasc Dis. 2006; 21:159-65. [PubMed: 16388190]

135. Flaherty ML, Kissela B, Woo D, et al. The increasing incidence of anticoagulant-associated intracerebral hemorrhage. Neurology. 2007; 68:116-21. [PubMed: 17210891]

136. Palareti G, Leali N, Coccheri S, et al. Bleeding complications of oral anticoagulant treatment: an inception-cohort, prospective collaborative study (ISCOAT). Italian Study on Complications of Oral Anticoagulant Therapy. Lancet. 1996; 48:23-28.

137. Rosand J, Hylek EM, O’Donnell HC, Greenberg SM. Warfarin-associated hemorrhage and cerebral amyloid angiopathy: a genetic and pathologic study. Neurology. 2000; 55:947-51. [PubMed: 11061249]

138. Sjoblom L, Hardemark HG, Lindgren A, et al. Management and prognostic features of intracerebral hemorrhage during anticoagulant therapy: a Swedish multicenter study. Stroke. 2001; 32:2567-74. [PubMed: 11692018]

139. Flibotte JJ, Hagan N, O’Donnell J, Greenberg SM, Rosand J. Warfarin, hematoma expansion, and outcome of intracerebral hemorrhage. Neurology. 2004; 63:1059-64. [PubMed: 15452298]

140. Yasaka M, Minematsu K, Naritomi H, Sakata T, Yamaguchi T. Predisposing factors for enlargement of intracerebral hemorrhage in patients treated with warfarin. Thromb Haemost. 2003; 89:278-83. [PubMed: 12574807]

141. Huttner HB, Schellinger PD, Hartmann M, et al. Hematoma growth and outcome in treated neurocritical care patients with intracerebral hemorrhage related to oral anticoagulant therapy: comparison of acute treatment strategies using vitamin K, fresh frozen plasma, and prothrombin complex concentrates. Stroke. 2006; 37:1465-70. [PubMed: 16675739]

142. Goldstein JN, Thomas SH, Frontiero V, et al. Timing of fresh frozen plasma administration and rapid correction of coagulopathy in warfarin-related intracerebral hemorrhage. Stroke. 2006; 37:151-55. [PubMed: 16306465]

143. Brody DL, Aiyagari V, Shackleford AM, Diringer MN. Use of recombinant factor VIIa in patients with warfarin-associated intracranial hemorrhage. Neurocrit Care. 2005; 2:263-67. [PubMed: 16159073]

144. Roitberg B, Emechebe-Kennedy O, Amin-Hanjani S, Mucksavage J, Tesoro E. Human recombinant factor VII for emergency reversal of coagulopathy in neurosurgical patients: a retrospective comparative study. Neurosurgery. 2005; 57:832-36. [PubMed: 16284552]

145. Rabinstein AA, Wijdicks EFM. Determinants of outcome in anticoagulation-associated cerebral hematoma requiring emergency evacuation. Arch Neurol. 2007; 64:203-06. [PubMed: 17172604]

146. Eckman MH, Rosand J, Knudsen KA, Singer DE, Greenberg SM. Can patients be anticoagulated after intracerebral hemorrhage? A decision analysis. Stroke. 2003; 34:1710-16. [PubMed: 12805495]

147. Keir SL, Wardlaw JM, Sandercock PA, Chen Z. Antithrombotic therapy in patients with any form of intracranial haemorrhage: a systematic review of the available controlled studies. Cerebrovasc Dis. 2002; 14:197-206. [PubMed: 12403952]

148. Butler AC, Tait RC. Restarting anticoagulation in prosthetic heart valve patients after intracranial haemorrhage: a 2-year follow-up. Br J Haematol. 1998; 103:1064-66. [PubMed: 9886320] 
149. Phan TG, Koh M, Wijdicks EF. Safety of discontinuation of anticoagulation in patients with intracranial hemorrhage at high thromboembolic risk. Arch Neurol. 2000; 57:1710-13. [PubMed: 11115236]

150. Priorities for clinical research in intracerebral hemorrhage: report from a National Institute of Neurological Disorders and Stroke workshop. Stroke. 2005; 36:e23-41. [PubMed: 15692109] 
Search strategy and selection criteria

We based our review on personal knowledge of the subject supplemented by data derived from multicentre randomised trials, and selected non-randomised or observational clinical studies. The information was identified with multiple searches on Medline from 2002 to the present by cross referencing the following keywords: "cerebral haemorrhage", "intracerebral hemorrhage", "neuroimaging", "clinical studies", "randomised trials", "cytotoxicity", "oedema", "haemostatic treatment", "factor VII", "acute hypertension", "surgery", "endoscopic evacuation", "stereotactic surgery", "intraventricular catheter", "hydrocephalus", and "oral anticoagulants". Other pertinent articles were identified through review of bibliography from selected articles. We also reviewed abstracts from pertinent scientific meetings. 


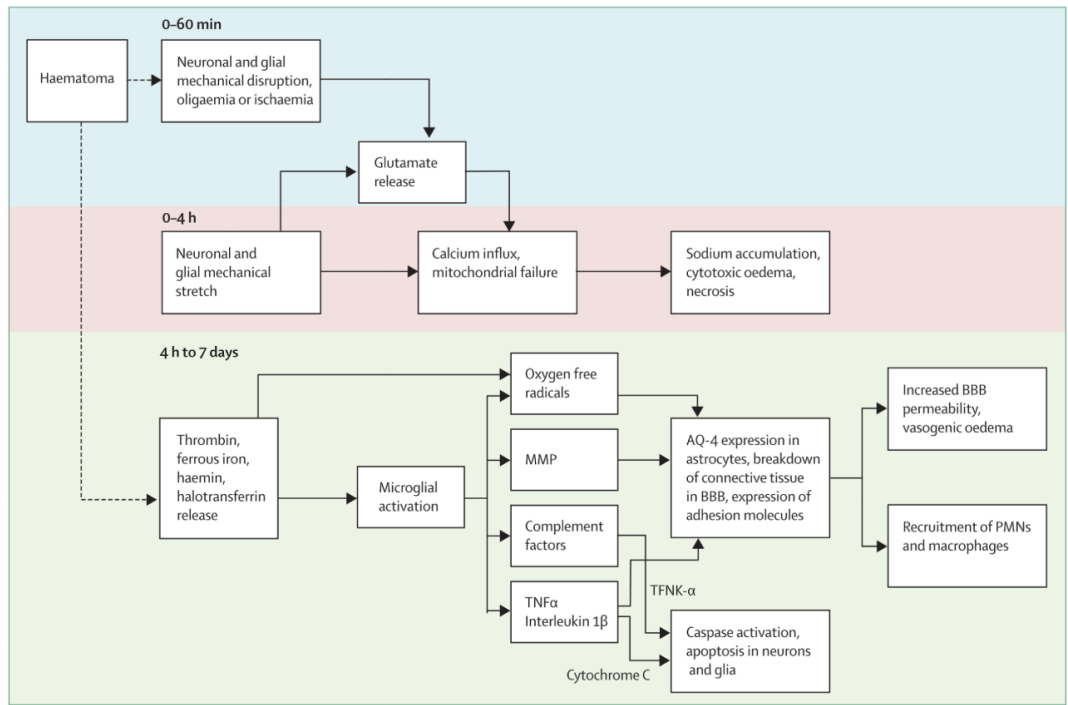

Figure 1. Cascade of neural injury initiated by intracerebral haemorrhage The steps in the first $4 \mathrm{~h}$ are related to the direct effect of the haematoma, later steps to the products released from the haematoma. $\mathrm{BBB}=$ blood-brain barrier. $\mathrm{MMP}=$ matrix metallopeptidase. $\mathrm{TNF}=$ tumour necrosis factor. $\mathrm{PMN}=$ polymorphonuclear cells. 

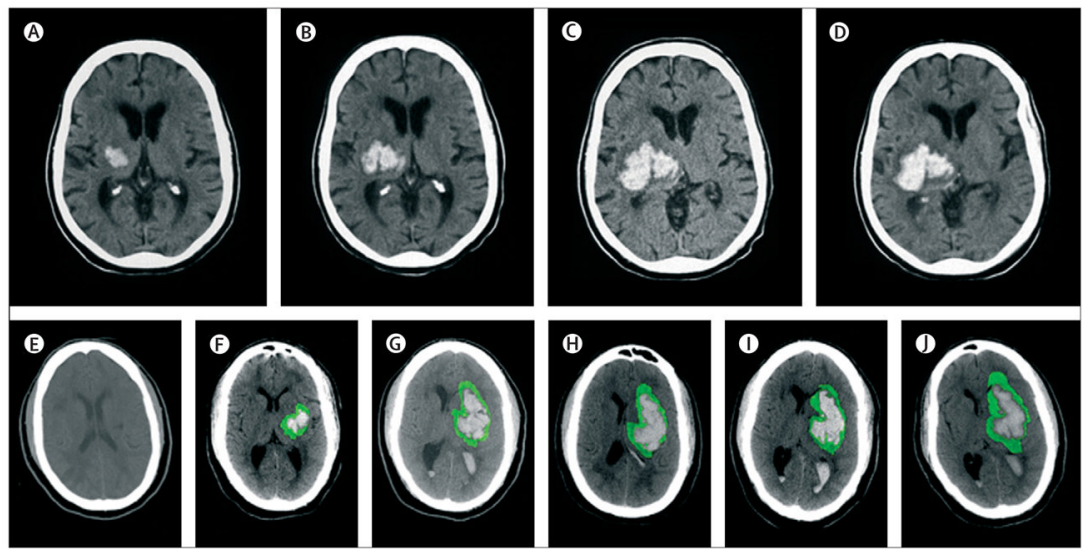

Figure 2. Progression of haemotoma and oedema on CT

Top: hyperacute expansion of haematoma in a patient with intracerebral haemorrhage on serial CT scans. Small haematoma detected in the basal ganglia and thalamus (A).

Expansion of haematoma after $151 \mathrm{~min}$ (B). Continued progression of haematoma after another $82 \mathrm{~min}$ (C). Stabilisation of haematoma after another $76 \mathrm{~min}$ (D). Bottom: progression of haematoma and perihaematomal oedema in a patient with intracerebral haemorrhage on serial CT scans. The first scan (E) was acquired before the intracerebral haemorrhage. Perihaematoma oedema is highlighted in green to facilitate recognition of progression of oedema. At $4 \mathrm{~h}$ after symptom onset there is a small haematoma in the basal ganglia (F). Expansion of haematoma with extension into the lateral ventricle and new masseffect and midline shift at $14 \mathrm{~h}(\mathrm{G})$. Worsening hydrocephalus and early perihaematomal oedema at $28 \mathrm{~h}(\mathrm{H})$. Continued mass-effect with prominent perihaematomal oedema at $73 \mathrm{~h}$ (I). Resolving haematoma with more prominent perihaematomal oedema at 7 days (J). 

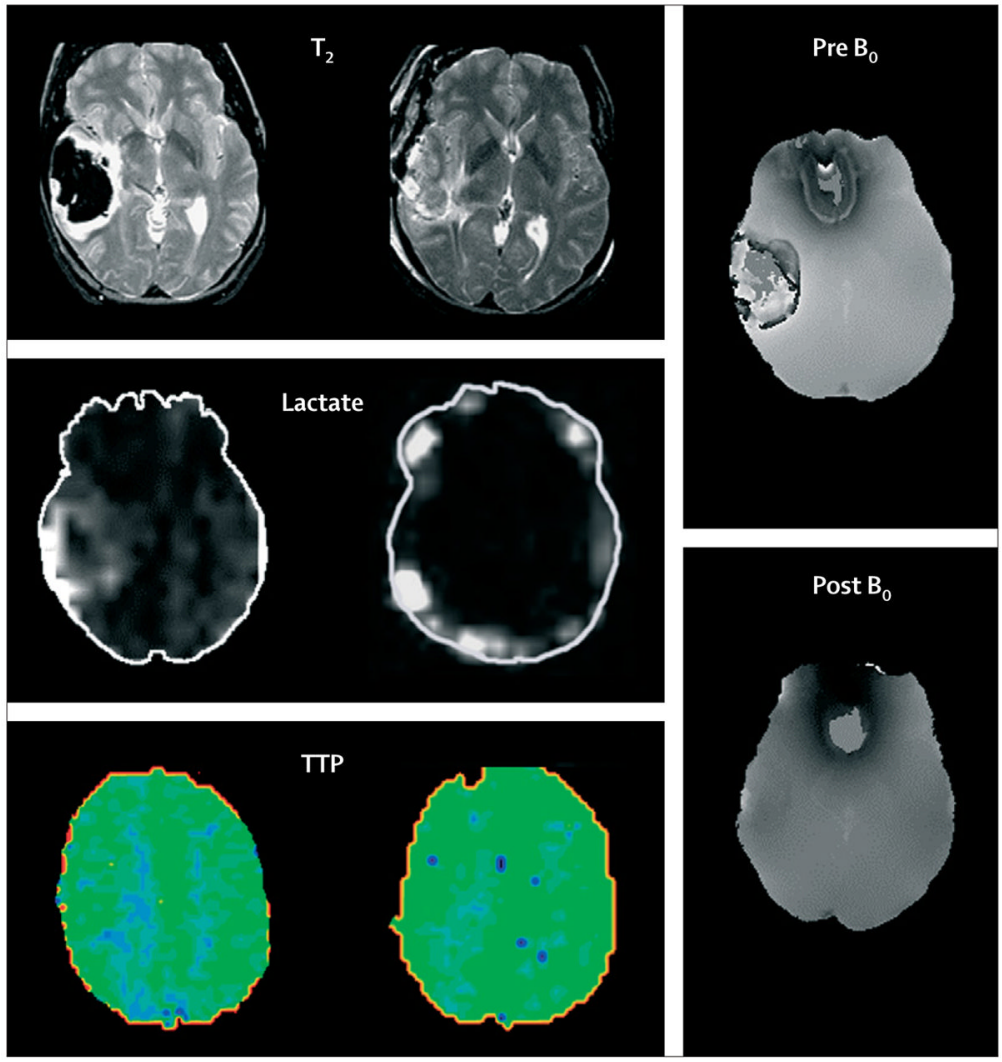

Figure 3. Advanced MRI of lobar intracerebral haemorrhage

Left: before craniotomy. Middle: after craniotomy for treatment of mass-effect and removal of haematoma. Sequential $\mathrm{T}_{2}$, lactate magnetic resonance spectroscopy, and perfusion studies showed qualitative decreases of perihaematomal oedema and perihaematomal lactate and increased occipital regional perfusion measured as time to peak of bolus injectate (TTP) after removal of clot; TTP is represented by intensity and distribution of green colour. Right: magnetic susceptibility images show paramagnetic influence before surgery and limited susceptibility after removal of the iron-containing blood clot by craniotomy. Figures provided by J Ricardo Carhuapoma (Johns Hopkins Medical Institution, Baltimore, MD, USA). 

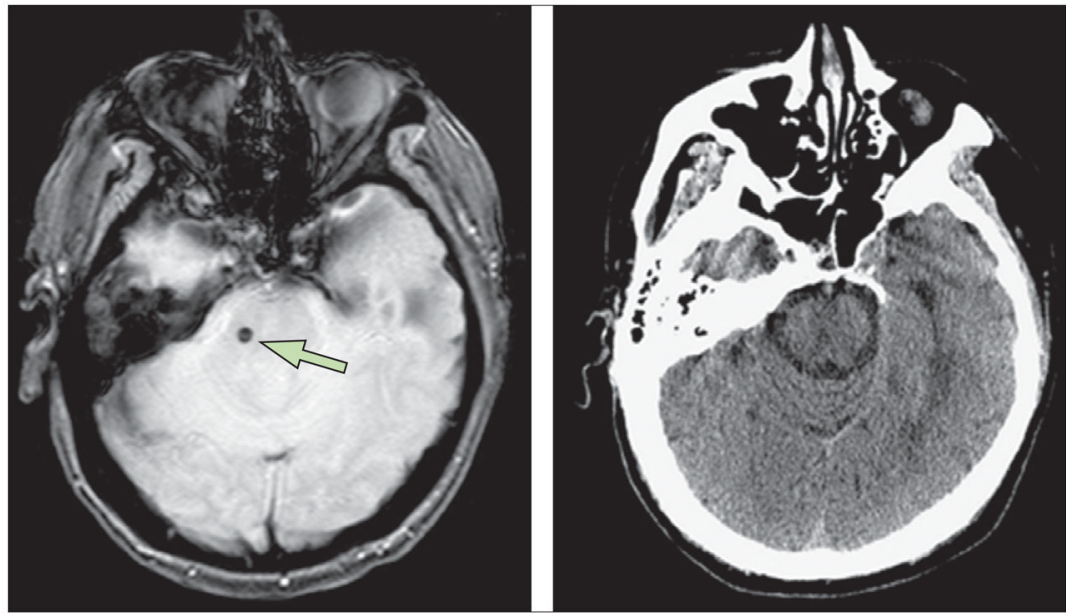

Figure 4. Detection of microhaemorrhages with MRI and CT scans

Left: asymptomatic pontine microbleed (arrow) in a patient with ischaemic stroke shown as focal hypointensity on gradient echo MRI. Right: microbleed not detected on CT scan. Figures are provided by David S Liebeskind (University of California at Los Angeles, CA, USA). 


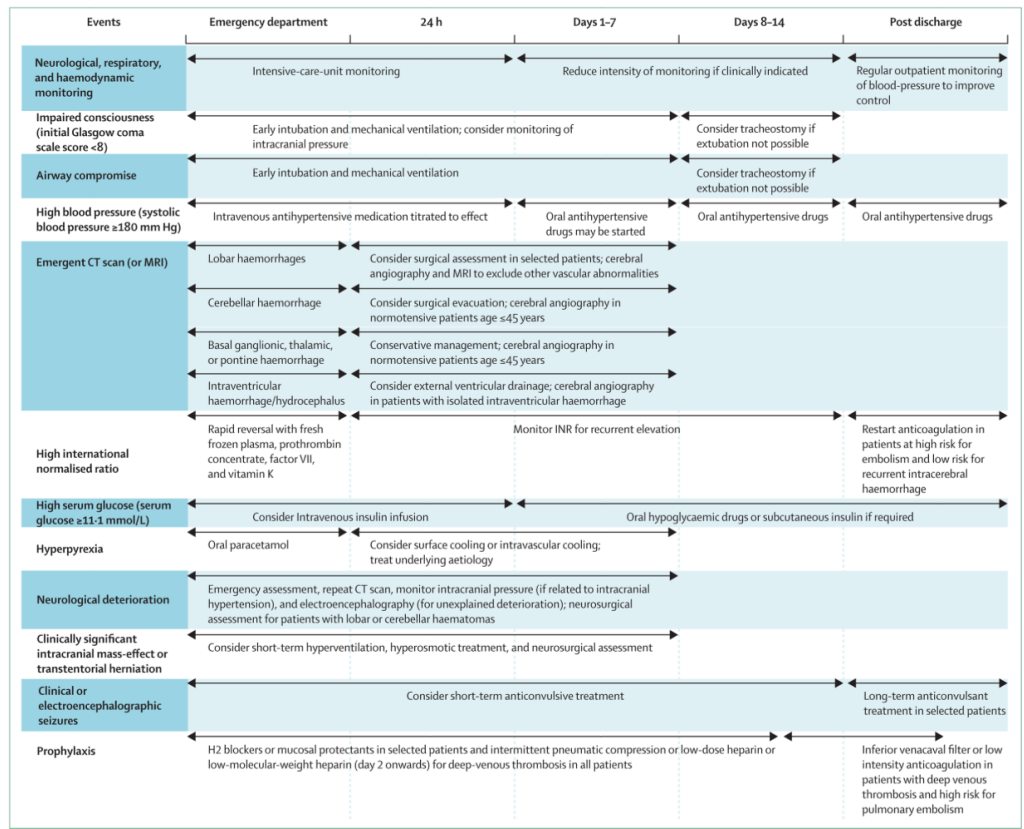

Figure 5.

Management algorithm for patients with intracerebral haemorrhage 


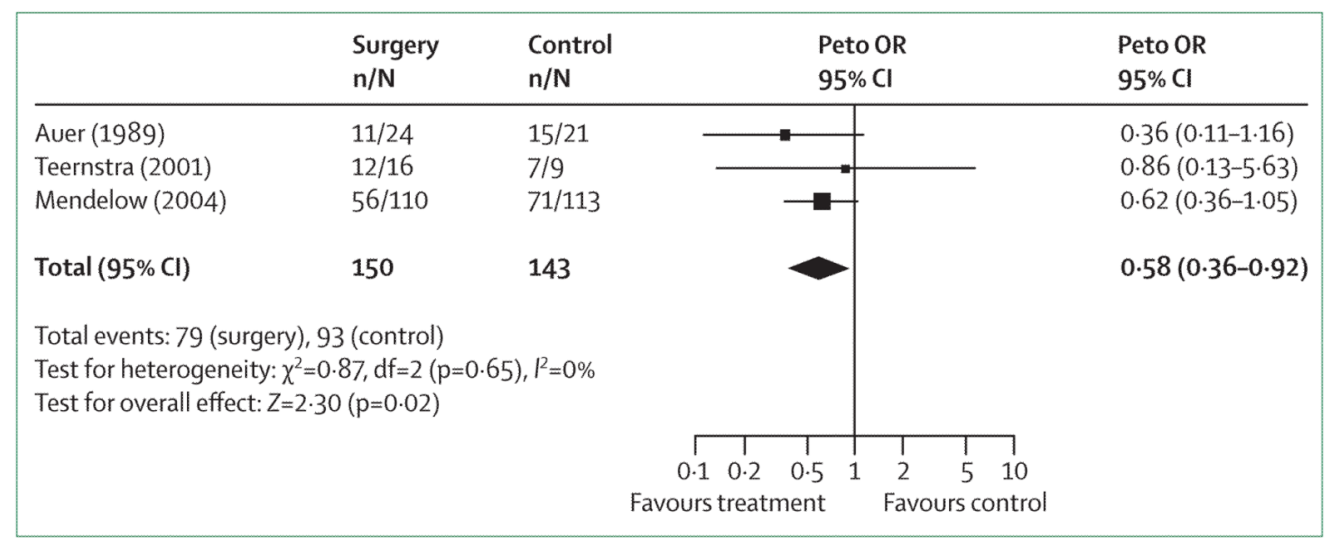

Figure 6. Odds ratio for death or disability in patients with lobar intracerebral haemorrhage treated surgically or conservatively

Boxes are Peto's odds ratio (OR), lines are $95 \%$ CI. Adapted with permission from Lippincott Williams and Wilkins. 108 